\title{
EFFECT OF HEAT TREATMENT PROCESSES ON WEAR BEHAVIOR OF TC21 TITANIUM ALLOY.
}

\author{
Ibrahim, K. M..$^{*}$ Barakat, A. F. ${ }^{\prime}$; Elshaer, R. . $_{.^{*}, \S}$ and Abbas, $R$. R. $^{\dagger}$ \\ *Central Metallurgical $R$ \& D Institute, Cairo, Egypt. \\ ${ }^{\dagger}$ Faculty of Engineering, Helwan University, Cairo, Egypt. \\ §Ramadan_elshaer@yahoo.com
}

\begin{abstract}
The effect of heat treatment on microstructure and wear behavior of TC21 (Ti-6Al-2Sn2Zr-3Mo-1Cr-2Nb-Si, wt.\%) Ti-alloy was investigated. The samples were solution treated at $900^{\circ} \mathrm{C}$ for $15 \mathrm{~min}$ followed by furnace cooling to $800^{\circ} \mathrm{C}$ with a cooling rate $1{ }^{\circ} \mathrm{C} / \mathrm{min}$ and holding for $20 \mathrm{~min}$, then the samples cooled down to room temperature either using water quenching (WQ) or air cooling (AC). Consequently, aging treatment was applied at $575^{\circ} \mathrm{C}$ for $4 \mathrm{hr}$. The microstructure feature showed a secondary $\alpha$ phase $\left(\alpha_{\mathrm{s}}\right)$ precipitated in residual $\beta$ phase due to the step cooling from $900^{\circ} \mathrm{C}$ to $800^{\circ} \mathrm{C}$ inside furnace as well as the aging treatment. The highest wear rate was obtained for WQ samples due to increasing in volume fraction of $\alpha_{p}(58 \%)$. However, the lowest wear rate was reported for WQ +Aging samples due to the high hardness.
\end{abstract}

Key Words: TC21 Ti-alloy; cooling rate; aging; microstructure; hardness; wear.

\section{INTRODUCTION}

Titanium alloys, especially $\alpha+\beta$ titanium alloys, are widely used in advanced aerospace applications, aero-engines and chemical industries. The combination of high strengthto-weight ratio, excellent mechanical properties and good corrosion resistance makes them the best material choices for some critical applications [1-3]. Titanium alloys were reported to present a notoriously poor wear characteristic due to their low resistance to plastic shearing, low working hardening and low protection exerted [4]. One of the main reasons behind poor tribological properties of titanium alloys is the low thermal conductivity [5]. The poor tribological behavior of titanium alloys is acting as high coefficients of friction, severe adhesive wear with a strong tendency to seizing and low abrasion resistance [6].

TC21 (Ti-6Al-2Sn-2Zr-3Mo-1Cr-2Nb-Si, wt.\%) alloy is a new category of $(\alpha+\beta)$ titanium alloys with high strength, toughness, and damage-tolerance properties. It belongs to eight-component system, which develops for structural application in advanced aircraft and aerospace [7]. In case using TC21 titanium alloy as important structural aircraft parts such as landing gear and flap track, there will be a significant advantage on weight loss for the aircraft. However, these components are subjected to two loads: the friction wear and alternating load. When their resistance to abrasion is improved, it must take account of the fatigue behavior [8]. Solution and aging treatments have been chosen to optimize microstructure and wear property of TC21 alloy by changing solution temperatures and cooling rate after solution treatment $[9$. 10]. By applying such solution and aging treatments, fine secondary $\alpha$-phase will precipitate inside the $\beta$ grains. 
Recently, a variety of studies investigated the effect of thermomechanical treatment [11], and oxidation treatment [12] on fatigue behavior of TC21 Ti-alloy [13]. However, detailed examination of the effect of heat treatment processes on wear behavior is rarely reported. Therefore, in the present study, the effect of applying heat treatment with different cooling rates on microstructure and wear properties of TC21 Ti- alloy has been investigated.

\section{EXPERIMENTAL WORK}

In this research, TC21 samples were received as bars with a diameter of $7 \mathrm{~mm}$ and 140 $\mathrm{mm}$ long. The $\beta$ transus temperature was experimentally determined that was approximately $960{ }^{\circ} \mathrm{C}$. The chemical composition of the as-received TC21 titanium alloy used in the present work is by weight percentage $\mathrm{Ti}-6.5 \% \mathrm{Al}-2.2 \% \mathrm{Sn}-2.2 \% \mathrm{Zr}$ $3 \% \mathrm{Mo}-1.5 \% \mathrm{Cr}-1.9 \% \mathrm{Nb}-0.09 \% \mathrm{Si}$. The samples were solution treated at $900^{\circ} \mathrm{C}$ for 15 min to achieve equilibrium followed by furnace cooled to $800^{\circ} \mathrm{C}$ with a cooling rate $1{ }^{\circ} \mathrm{C} / \mathrm{min}$ and holding for $20 \mathrm{~min}$. Then the samples cooled either using water quenching or air cooling. Consequently, aging treatment was applied at $575^{\circ} \mathrm{C}$ for $4 \mathrm{hr}$. The experimental procedure for the heat treatment process is shown in figure 1 . The samples for optical metallographic examination were prepared by mechanical polishing and then etching with a solution consisting of $3 \% \mathrm{HF}, 30 \% \mathrm{HNO}_{3}$ and $67 \% \mathrm{H}_{2} \mathrm{O}$.

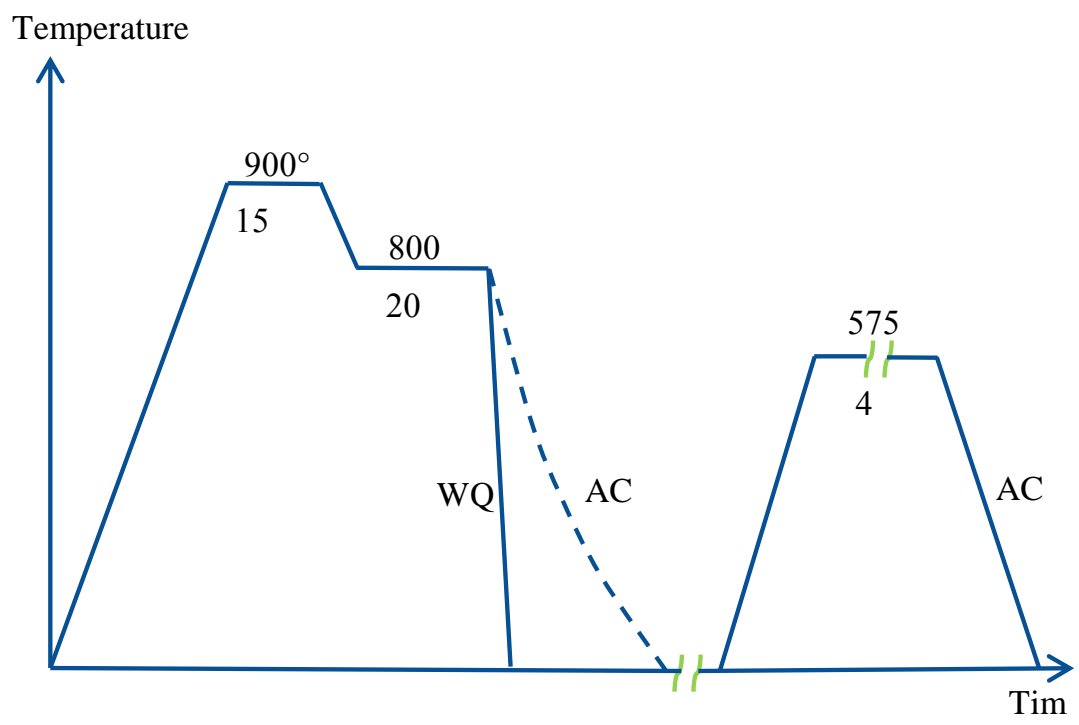

Fig. 1: Experimental procedure for the heat treatment.

Vickers hardness measurements were carried out using Vickers hardness tester in accordance to ASTM E384-11 standard, with a load of $196 \mathrm{~N} \mathrm{(20} \mathrm{kg)} \mathrm{for} 15 \mathrm{~s}$. Dry sliding wear test was conducted using pin-on-ring tribometer testing machine in accordance to ASTM G99-05 standard. The wear sample with a cylindrical shape of 7 $\mathrm{mm}$ in diameter and $12 \mathrm{~mm}$ long was fixed against a rotating hardened ring (outer diameter of $73 \mathrm{~mm}$ and surface hardness of $63 \mathrm{HRC}$ ). Prior to each test, sample and counterpart surfaces were ground with different emery papers up to 1000 grit and cleaned ultrasonically in acetone to avoid the presence of humidity and non-desirable deposits. The ring was rotated at different speeds, which yielded a linear sliding speed 
of $1,1.25,1.5,1.75$ and $2 \mathrm{~m} / \mathrm{s}$. An applied constant normal load of $20 \mathrm{~N}$ was used for duration of $15 \mathrm{~min}$. During testing, a jet of compressed air was pointed at the edge of the ring to avoid accumulation of wearing debris on the ring. The weights of samples were measured before and after testing using electronic scales with $0.1 \mathrm{mg}$ accuracy. The test results were evaluated according to the loss in weight. The mean value of results from three experiments has been reported. Worn surface of some selected samples was examined and analyzed using XRD and FESEM in order to determine the post-experimental wear mechanisms.

\section{RESULTS AND DISCUSSION}

\subsection{Microstructure Evolution}

\subsubsection{Solution treated condition}

The microstructure of solution treated TC21 samples followed by either WQ or AC is shown in figure 2 . Generally, the volume fraction of primary equiaxed alpha phase $\left(\alpha_{p}\right)$ increases with increasing of cooling rate. In addition, secondary alpha phase $\left(\alpha_{\mathrm{s}}\right)$ precipitated during the step cooling from $900^{\circ} \mathrm{C}$ to $800^{\circ} \mathrm{C}$. However, $\alpha_{\mathrm{s}}$ does not form during WQ due to high cooling rate that generates a high supersaturation in WQ condition as a result of diffusion of $\beta$ stabilizing elements in the $\beta$ phase. Subsequently, these elements will hinder the precipitation of secondary $\alpha$ phase. Step cooling in furnace mainly affects the growth of primary $\alpha$ phase and precipitation of secondary $\alpha$ phase. For WQ condition, the grain size of primary $\alpha$ phase was in the range of $3.05 \mu \mathrm{m}$ and the volume fraction was about $58 \%$, and those in AC condition increased to 4.08 $\mu \mathrm{m}$ and decreased to $52 \%$, respectively.

Precipitation of secondary $\alpha$ phase at AC condition is due to increasing in cooling time. Therefore, it could be concluded that precipitation of secondary $\alpha$ phase could be obtained in a large amount by lower the cooling rate (AC) or applying a step cooling during solution treatment. Hence, a proper supersaturation could be considered as a critical factor for precipitation of secondary $\alpha$ phase in heat-treating of TC21 alloy. Based on the above discussion, the microstructure after WQ and AC conditions consists of primary equiaxed $\alpha$ phase, secondary $\alpha$ phase and transformed $\beta$ phase.

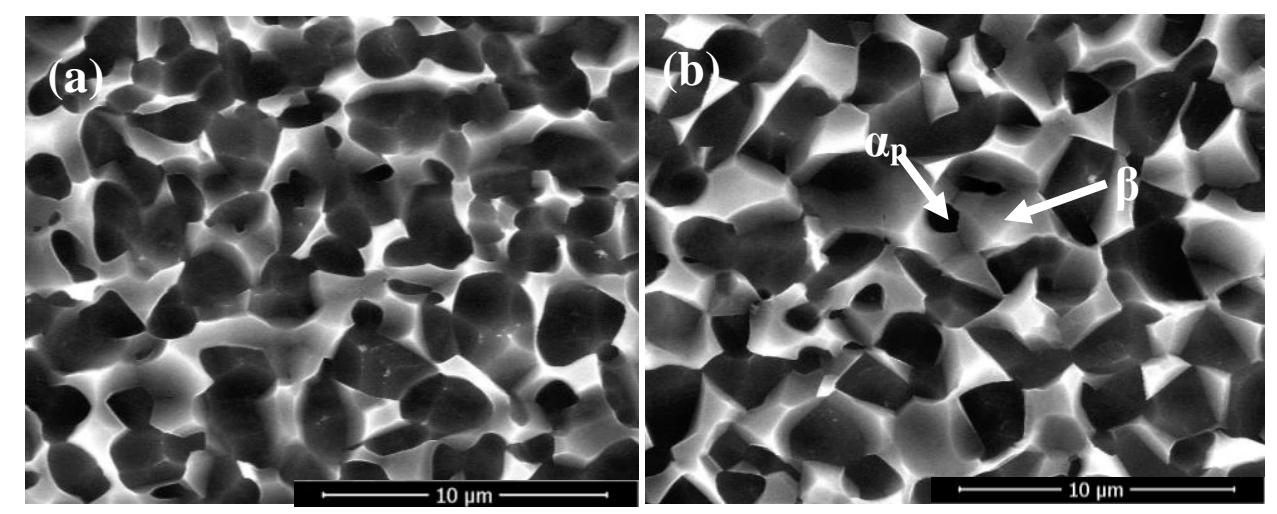

Fig. 2: FESEM micrographs showing the microstructures of the conditions: (a) WQ and (b) AC. 


\subsubsection{Solution treated + aging condition}

Solution treatment and aging is considered one of the processes usually applied on TC21 alloy [10]. The as-aged structure composed of an equiaxed $\alpha_{\mathrm{p}}$ distributed homogenously in the $\beta$ matrix, figure 3 . For $\mathrm{AC}+$ Aging, $\alpha_{\mathrm{s}}$ with a gray contrast precipitated in the residual $\beta$ matrix due to step cooling in furnace and also slow cooling rate as well as aging treatment (figure 3a). The volume fractions of $\alpha_{\mathrm{p}}$ and $\alpha_{\mathrm{s}}$ are about 45 vol. $\%$ and 20 vol. $\%$, respectively. For WQ +Aging, $\alpha_{\text {s }}$ precipitated in the residual $\beta$ matrix due to step cooling in furnace and aging treatment (figure $3 b$ ). The volume fractions of $\alpha_{\mathrm{p}}$ and $\alpha_{\mathrm{s}}$ are about 40 vol.\% and 15 vol.\%, respectively. Moreover, fine secondary $\alpha$ platelets were precipitated from the supersaturated $\beta$ phase during solution treatment and aging, figure 4 . These precipitations of $\alpha_{\mathrm{s}}$ platelets are regarded as the main reason for strengthening the studied TC21 alloy [14]. This is because these $\alpha_{\mathrm{s}}$ platelets will increase the $\alpha / \beta$ phase boundary. Fine secondary $\alpha$ platelets together with residual $\beta$ phase are called "residual $\beta$ matrix strengthened by fine secondary $\alpha$ platelets" ("residual $\beta$ matrix" for short). This result was in agreement with the results that were reported by SHAO et. al [14].
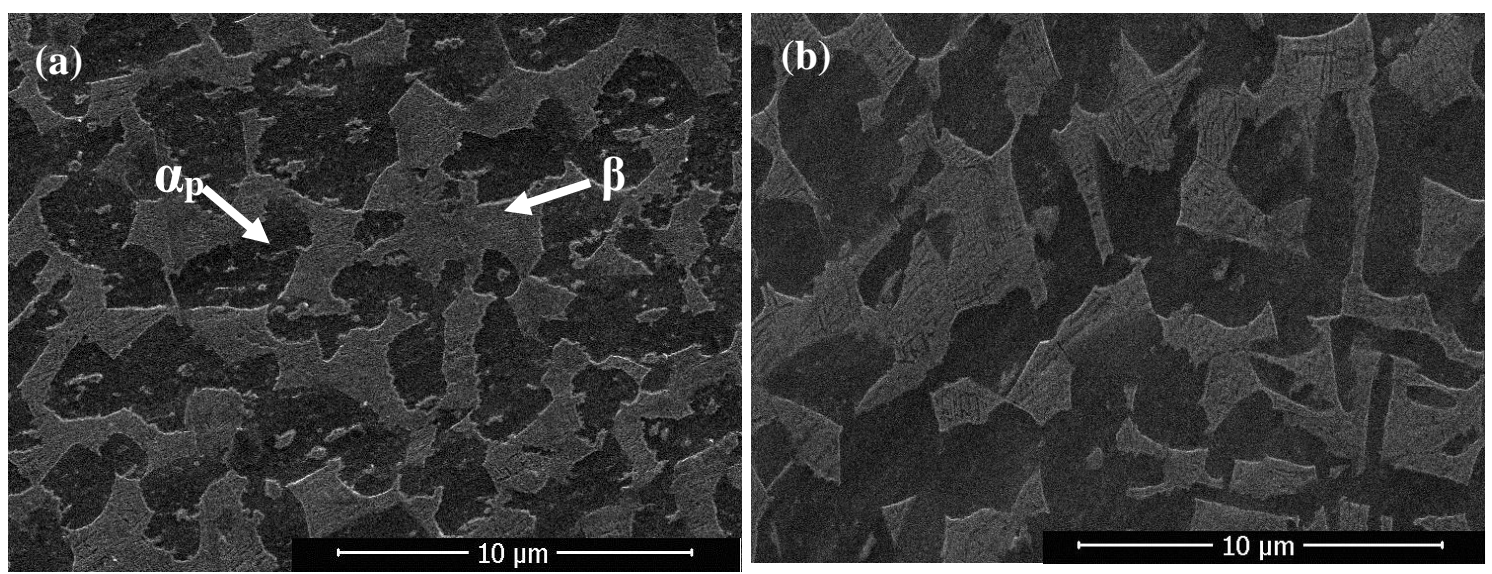

Fig. 3: FESEM images of aged samples: (a) AC+ Aging and (b) WQ +Aging.

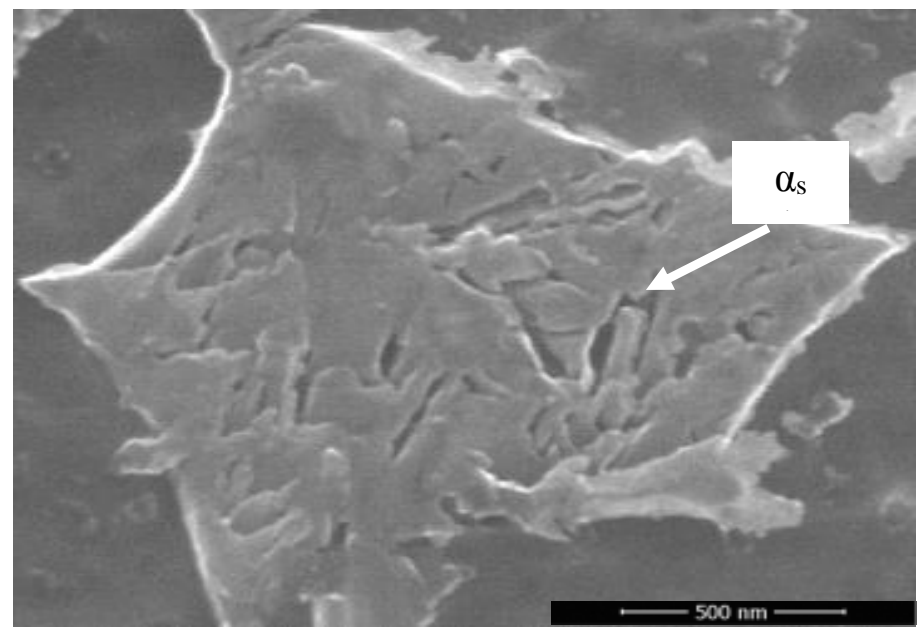

Fig. 4: Fine secondary $\alpha$ platelets in residual $\beta$ matrix. 


\subsection{Mechanical Properties}

\subsubsection{Hardness}

Vickers hardness measurements were carried out to investigate the influence of solution and aging treatments on the as-received TC21 alloy, figure 5. WQ samples obtained the lowest hardness (HV340) due to the presence of high amount of $\alpha_{p}$ phase (58\%). While, AC samples revealed a higher hardness (HV348) compared to WQ samples due to existing of a lower amount of $\alpha_{p}$ phase (52\%). AC+ Aging samples showed a hardness value of HV395. Moreover, WQ +Aging samples obtained the highest hardness value (HV438) due to the presence of a lower amount of $\alpha_{p}$ phase (40\%) compared to the others. It is also noticed that cooling rate has a relatively small effect on the hardness of TC21 alloy. The variation in hardness with aging treatment is more pronounced. There is an increase in hardness of $29 \%$ in case of WQ +Aging condition compared to WQ condition. Based on hardness results, it can be expected that WQ +Aging condition will show better tribological performance than other conditions.

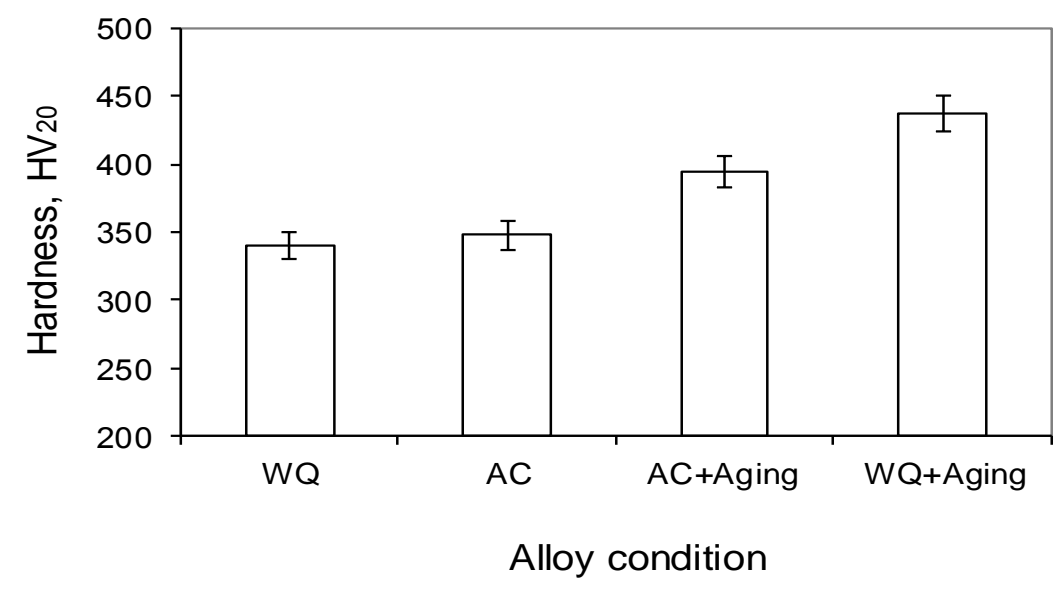

Fig. 5: Average hardness values at various conditions.

\subsubsection{Wear properties}

The effect of sliding speed on wear rate of the studied TC21 alloy in all conditions is presented in figure 6 . The estimated wear rates obtained that wear rate for all studied conditions increased with increasing sliding speed up to $1.75 \mathrm{~m} / \mathrm{s}$ and then decreased again at $2 \mathrm{~m} / \mathrm{s}$. Since the wear rate is directly proportional to the real area of contact, WQ +Aging samples showed a lower wear rate. However, WQ samples obtained the highest wear rate compared to the others. The wear rate of WQ samples was approximately one and half times higher than WQ +Aging samples. This may be expected for the as-aged samples, irrespective of microstructure, where they exhibited higher hardness as compared to the samples without aging.

The wear rate of all conditions significantly can be classified into three stages with increasing sliding speed, figure 6. Initially, the wear rate was rapidly increased with increasing sliding speed up to $1.5 \mathrm{~m} / \mathrm{s}$, and then showed a steady state until $1.75 \mathrm{~m} / \mathrm{s}$ and 
finally deterioration with further increase in sliding speed up to $2 \mathrm{~m} / \mathrm{s}$. As shown in figure 6 , stage I showed high wear rate because of the first contact between the sample and rotating ring. In such case, the wear rate will be high until coinciding sample surface with the rotating ring. Because WQ samples had a low hardness, they showed a high amount of wear rate in stage I. If the sample surface coincided well with the rotating ring, the wear rate will reach a steady state, which is denoted as stage II. With increasing sliding speed to $2 \mathrm{~m} / \mathrm{s}$, the temperature of contact surface will be increased. Then, a relative thermal hardening effect will be happened and the wear rate will be decreased. This phase is defined as stage III.

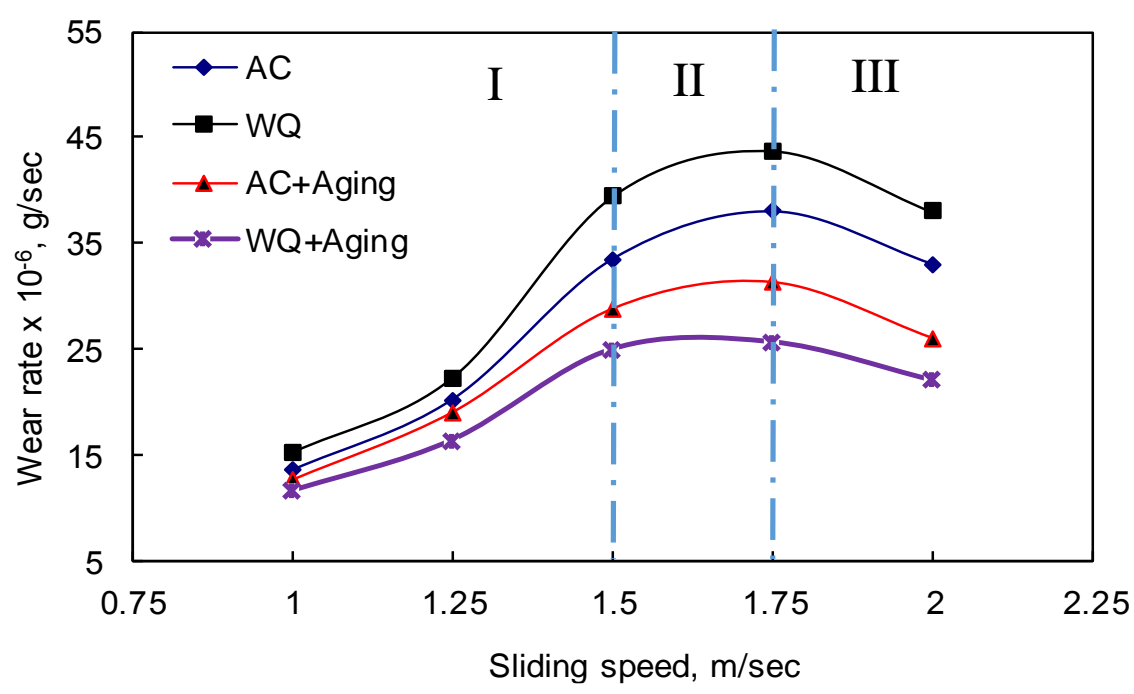

Fig. 6: Wear rate of studied TC21 alloy as a function of sliding speed.

When the sample surface is first brought into contact with the rotating ring, the wear occurs by removal of high amount of asperities and then initial oxide layer will be formed over the surface. In general, a harder material is able to hold a thicker oxide layer more firmly as compared to a softer one [15]. Hence, WQ +Aging condition, which is harder than the others, may be able to hold an oxide layer of a larger critical thickness firmly before it flakes off. Continuing the process of oxide layer removal and reformation as well as thickening, there will be a variation in wear rate. Increasing the difference in wear rate at higher sliding speeds as compared to lower speeds may be explained based on oxide layer formation. This is supported by the XRD analysis that has been done on the worn surface samples at different sliding speeds for WQ condition, figure 7. XRD analysis showed some diffraction peaks for metallic material and there were no peaks for Fe that transferred from the ring to TC21 samples. As can be seen from figure $7 \mathrm{a}$, at lower sliding speed $(1 \mathrm{~m} / \mathrm{s})$, only $\alpha$-Ti was the predominant and no oxides could be recognized. In contrast, the XRD patterns at higher sliding speeds $\left(1.75\right.$ and $2 \mathrm{~m} / \mathrm{s}$ ) showed some particles of $\mathrm{TiO}_{2}$ and $\mathrm{Al}_{2} \mathrm{O}_{3}$ oxides that were existing on the worn surfaces (figures $7 b, c)$. The amount of these oxides was relatively very small. 

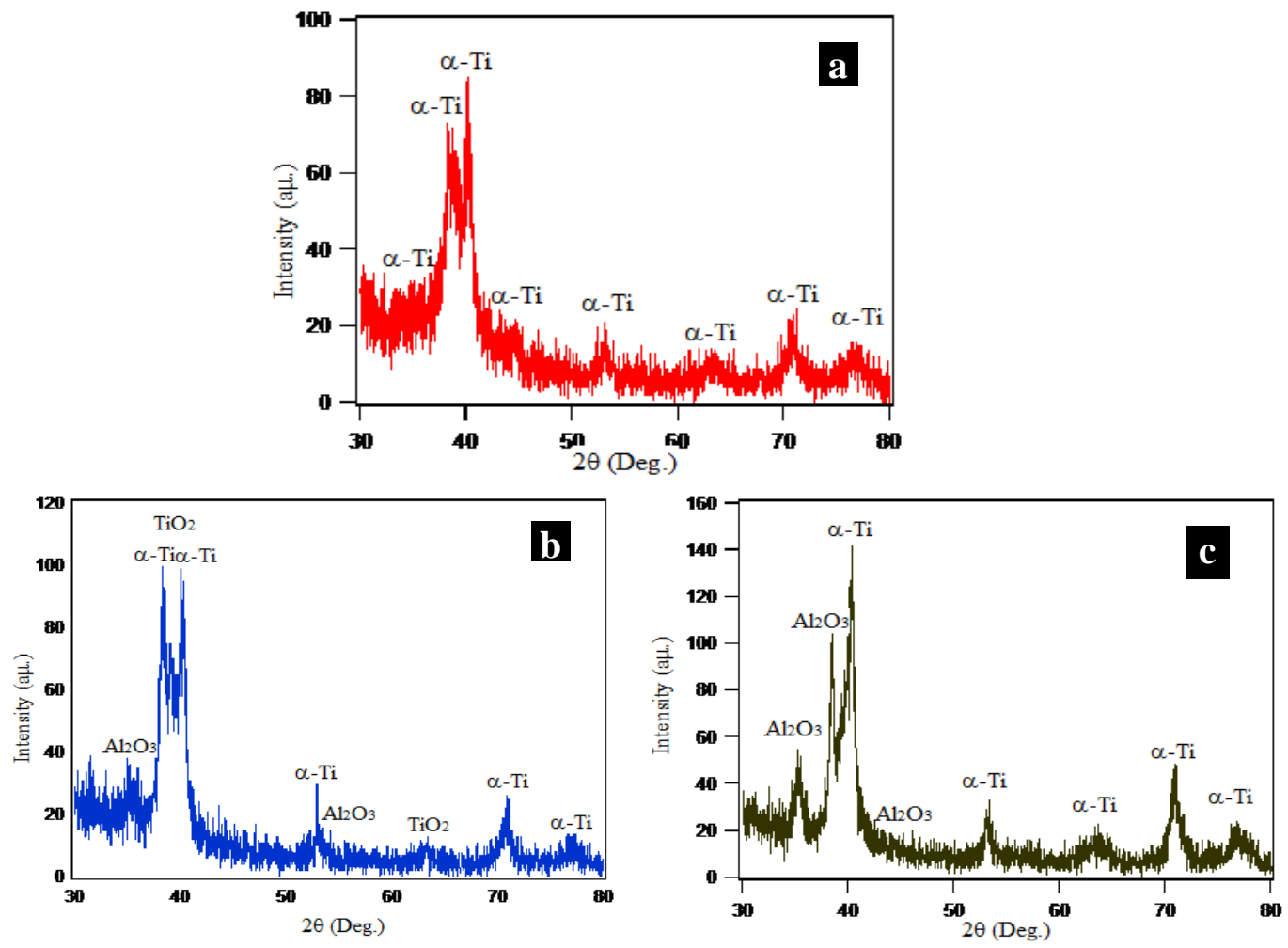

Fig. 7: XRD patterns of the worn surface at speeds of (a) $1 \mathrm{~m} / \mathrm{s}$, (b) $1.75 \mathrm{~m} / \mathrm{s}$ and (c) $2 \mathrm{~m} / \mathrm{s}$.

The FESEM micrographs presented in figures 8 and 9 showed worn surface morphologies for the samples tested at WQ and WQ +Aging conditions with different sliding speeds $(1,1.75$ and $2 \mathrm{~m} / \mathrm{s})$. The morphologies of worn surfaces at intermediate sliding speeds $(1.25$ and $1.5 \mathrm{~m} / \mathrm{s})$ are not included in this study because they showed intermediate characteristics between those chosen three extremes. Evidences of abrasion wear can be detected in all tested samples. Continuous sliding marks with plastically deformed grooves and ridges were seen on wear tracks independently of sliding speed. Extent of plastic deformation or "ploughing" is found to be smaller in case of WQ +Aging condition. Layers with plastic deformation were found over the worn surfaces with relatively smooth areas for all sliding speeds.

The worn surfaces of WQ condition (figure 8) showed rough worn surfaces, abrasive grooves with extensive plastic deformation and traces of local material removal by delamination process. These worn surfaces indicated actually to severe wear. Moreover, some fracture and large flakes removed from the worn surface were observed. Detailed investigation for delaminated regions reveals ridges and many cracks at either parallel or right angle to sliding direction as indicated by arrows in figure $8 \mathrm{~d}$. Closer observation of wear tracks reveals also large flakes removed from the surface (figures 8d, f), which indicated to delamination wear mechanism. This is probably due to a relatively greater contact between the sample and rotating ring. In addition, discrete patches of material smeared can be easily detected on the worn surfaces. These features indicated to the wear that 
occurred predominantly by adhesion. In such case, adhesion overlaps the abrasion and accelerated the wear process for WQ condition.
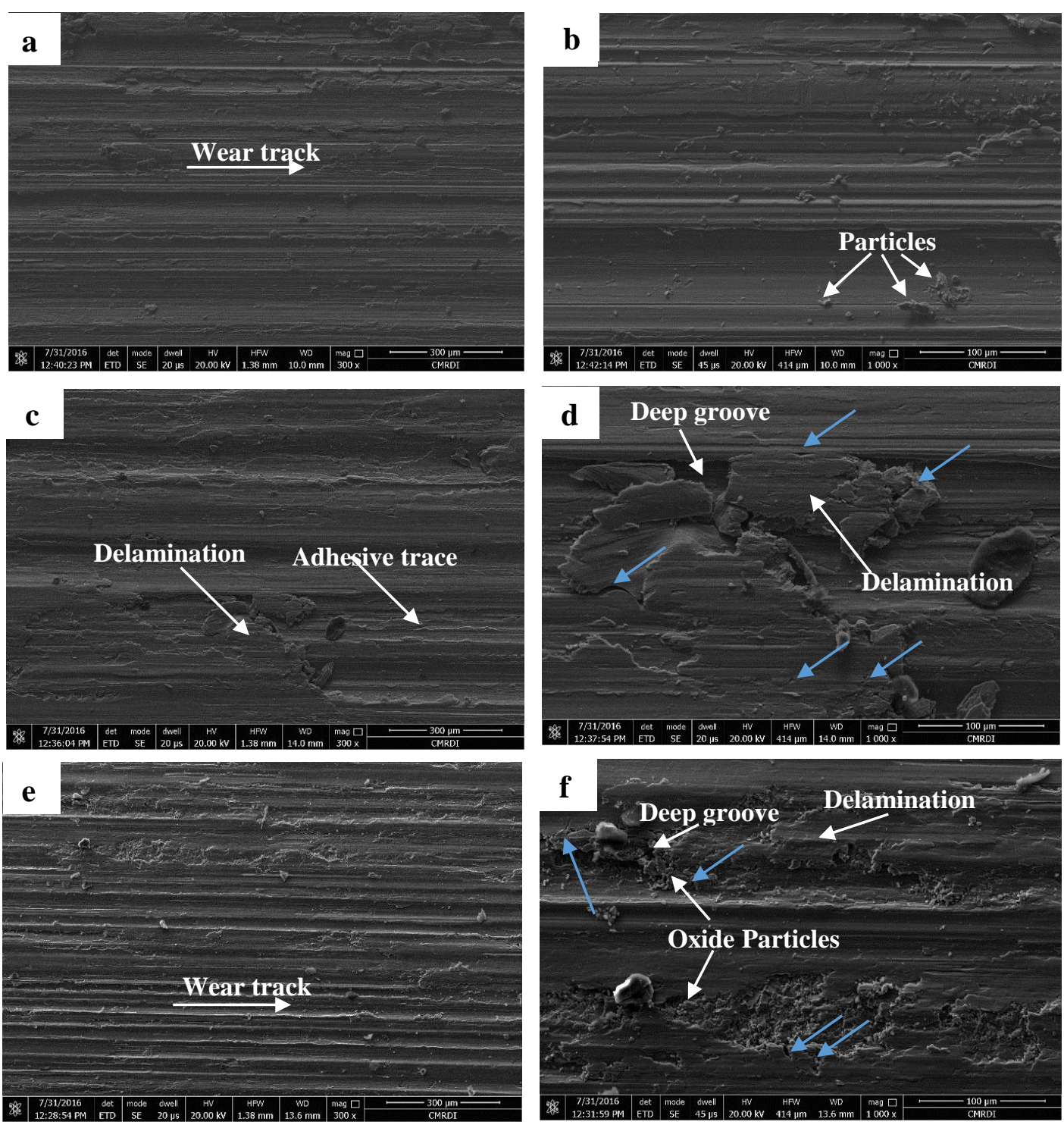

Fig. 8: Worn surfaces of the WQ at $1 \mathrm{~m} / \mathrm{s}(\mathrm{a}, \mathrm{b}), 1.75 \mathrm{~m} / \mathrm{s}(\mathrm{c}, \mathrm{d})$ and $2 \mathrm{~m} / \mathrm{s}(\mathrm{e}, \mathrm{f})$.

Although there was some moderate adhesive wear damage, it was evident that two wear mechanisms, abrasive and adhesive, were more pronounced at low speeds. The ring surface was also examined to prove this phenomenon. The same wear mechanism was observed by examining sample worn surfaces at a low speed of $1.0 \mathrm{~m} / \mathrm{s}$ (figures $8 \mathrm{a}, \mathrm{b}$ ). Formation and removal of transferred layers produced by delamination wear and an increase in the amount of wear rate, which was much higher than the other conditions. It is obvious that wear behavior of WQ condition strongly depends on its hardness. Occurrence of delamination was more prominent when wear tests are carried out at high sliding speeds of 1.75 and $2 \mathrm{~m} / \mathrm{s}$ (figures $8 \mathrm{~d}-\mathrm{f}$ ). The same behavior was observed by Cvijović et al [15], who found that adhesive wear mechanism was dominant in wear testing of Ti-Nb-Zr alloy. 
The worn surface morphology of WQ +Aging condition is shown in figure 9. WQ +Aging worn surfaces showed similar worn surfaces feature as WQ samples. Noticeable 'ploughing' was found, irrespective of the tribological sliding speeds. Continuous damaged layers in a brittle manner and abrasive grooves aligned in the direction of sliding can be clearly detected (figures 9a, c, e). It could be suggested that abrasive wear mechanism was mainly pronounced. FESEM investigation of WQ +Aging worn surfaces showed delamination with a lower degree of severity and some patches of smeared material (figures 9c, d). Each type of damage was observed in various degrees on the worn surfaces at different sliding speeds. Patches of smeared material found to decrease as sliding speed is increased to $2.0 \mathrm{~m} / \mathrm{s}$ (figures $9 \mathrm{e}, \mathrm{f}$ ). Smooth appearance of worn surface and small extent of plastic flow were the indication of getting better resistance of WQ +Aging samples to plastic deformation compared to WQ samples. As can be seen in figure 9, the severity of abrasion was significantly lower. This may be expected, since the wear rate of WQ +Aging samples was one and half orders in magnitude lower than of WQ samples. The presence of patches and traces of local material removal could not be easily detected, especially on the worn surfaces tested at low sliding speed (figures $9 \mathrm{a}, \mathrm{b}$ ).
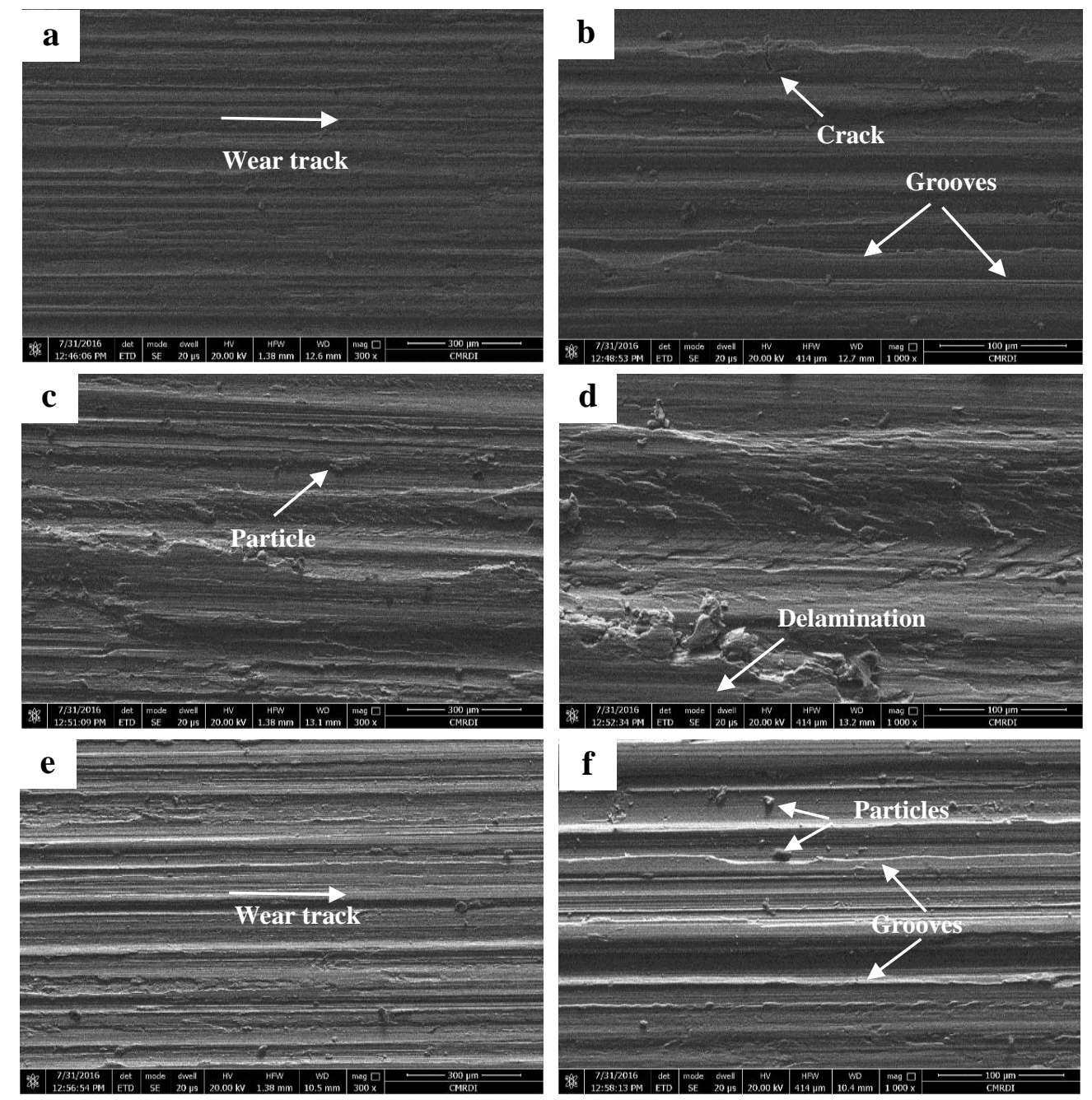

Fig. 9: Worn surfaces of the WQ +Aging at $1 \mathrm{~m} / \mathrm{s}(\mathrm{a}, \mathrm{b}), 1.75 \mathrm{~m} / \mathrm{s}(\mathrm{c}, \mathrm{d})$ and $2 \mathrm{~m} / \mathrm{s}(\mathrm{e}, \mathrm{f})$. 


\section{Conclusions}

From the experimental results related to microstructure and wear characteristics of TC21 alloy subjected to different heat treatment processes, the following conclusions can be drawn:

- Heat treatment with two different cooling rates and aging treatment, produced a structure consisted of secondary $\alpha$ phase precipitated in a residual $\beta$ phase due slow cooling rate from $900^{\circ} \mathrm{C}$ to $800^{\circ} \mathrm{C}$ inside furnace or the final slow cooling rate by air as well as the aging treatment. Fine secondary $\alpha$ platelets and residual $\beta$ phase formed a residual $\beta$ matrix.

- Cooling rate has a relatively small effect on hardness of the studied TC21 alloy. The variation in hardness with aging treatment was more pronounced.

- Microstructure of TC21 alloy composed mainly of $\alpha$ phase and residual $\beta$ matrix strengthened by secondary $\alpha$ platelets.

- The highest wear rate was obtained for WQ condition. However, the lowest wear rate was given for WQ +Aging condition due to its high hardness. In addition, wear rate of all conditions increased with increasing sliding speed until $1.75 \mathrm{~m} / \mathrm{s}$ and then decreased with increasing sliding speed of $2 \mathrm{~m} / \mathrm{s}$.

- Abrasion wear mechanism was noticed in WQ +Aging samples. Adhesion, transfer layer formation and cracking wear mechanisms were observed in case of WQ samples. At low sliding speed, microfragmentation wear mechanism was observed, and brittle detachment of large particles wear mechanism was obtained at high sliding speed.

\section{REFERENCES}

[1] Lütjering, G. and Williams, J. C.: "Titanium". $2^{\text {nd. }}$ edition, Springer, Berlin Heidelberg, (2007).

[2] Banerjee, D. and Williams, J. C.: "Perspectives on titanium science and technology". Acta Materialia, vol. 61, pp. 844-879, (2013).

[3] Ibrahim, K. M.; EL-Hakeem, A. M. and Elshaer, R. N.: "Microstructure and mechanical properties of cast and heat treated Ti-6.55Al-3.41Mo-1.77Zr alloy". Transactions of nonferrous metals society of China, vol. 23, pp. 3517-3524, (2013).

[4] Wang, L.; Zang, Q. Y.; Li, X. X.; Cui, X. H. and Wang, S. Q.: "Severe-to-mild wear transition of titanium alloys as a function of temperature". Tribology letters, vol. 53, pp. 511-520, (2014).

[5] Zang, Q. Y.; Zhou Y.; Li, X. X.; Wang, L.; Cui, X. H. and Wang, S. Q.: "Accelerated formation of tribo-oxide layer and its effect on sliding wear of a titanium alloy". Tribology letters, vol. 63, pp. 1-13, (2016).

[6] Ceschini, L.; Lanzoni, E.; Martini, C.; Prandstraller, D. and Sambogna, G.: "Comparison of dry sliding friction and wear of Ti6Al4V alloy treated by plasma electrolytic oxidation and PVD coating". Wear, vol. 264, No. 1-2, pp. 86-95, (2008).

[7] Tang, B.; Kou, H.; Wang, Y.; Zhu, Z.; Zhang, F. and Li, J.: "Kinetics of orthorhombic martensite decomposition in TC21 alloy under isothermal conditions". Journal of materials science, vol. 47, pp. 521-529, (2012).

[8] Xing, D. D.; Xin, L. D.; Li, M. B. and Hua1, Z. X.: "Effects of pretreatment and HVOF sprayed cermet coating on fatigue properties of TC21 titanium alloy", Science China technological sciences, vol. 56, pp. 1029-1037, (2013). 
[9] Wen, L.; Xiao, M.; Zhi, H.; Ya, L.; Heng, Q.; Yi, Z. and Zheng, X.: "Effect of heat treatment on microstructures and mechanical properties of TC21 alloy large bar". Titanium industry process, vol. 27, pp. 28-31, (2010).

[10] Shi, Z. F.; Guo, H. Z.; Han, J. Y. and Yao, Z. K.: "Microstructure and mechanical properties of TC21 titanium alloy after heat treatment". Transactions of nonferrous metals society of China, vol. 23, pp. 2882-2889, (2013).

[11] Shi, Z. F.; Guo, H. Z.; Liu, R.; Wang, X. C. and Yao, Z. K.: "Microstructure and mechanical properties of TC21 titanium alloy by near-isothermal forging". Transactions of nonferrous metals society of China, vol. 25, pp. 72-79, (2015).

[12] Jia, Z.; Zeng, W.; Zha, Y.; Shi, C.; Qua, B. and Wu, J.: "The color changes and tensile properties of oxidized Ti-6A1-2Mo-1.5Cr-2Zr-2Sn-2Nb alloy". Journal of alloys and compounds, vol. 640, pp. 488-496, (2015).

[13] Tan, C.; Li, X.; Sun, Q.; Xiao, L.; Zhao, Y. and Sun, J.: "Effect of $\alpha$-phase morphology on low-cycle fatigue behavior of TC21 alloy". International journal of fatigue, vol. 75, pp. 1-9, (2015).

[14] Shao, H.; Zhao, Y.; Ge, P. and Zeng, W.: "Crack initiation and mechanical properties of TC21 titanium alloy with equiaxed microstructure". Materials science \& engineering A, vol. 586, pp. 215-222, (2013).

[15] Cvijović-Alagić, I.; Cvijović, Z.; Mitrović, S.; Rakin, M.; Panić, Đ. and Babić, M.: "Wear and corrosion behavior of Ti-24Al-11Nb and Ti-6Al-4V alloys in simulated physiological solution". Corrosion science, vol. 53, pp. 796-808, (2011). 